\title{
Fertility Expectations: \\ A Short Cut or Dead-End in Predicting Fertility?
}

TURID NOACK

LARS OSTBY

Anyone who wants to describe, explain or predict short-term fertility trends, has to bear in mind the different types of fertility measures, and decide on the most suitable one for the purpose. Period fertility measures make it possible to feel the pulse of fertility alterations. Cohort-fertility measures will always give descriptions and explanations which will tend to lag behind what is going on at the moment. On the other hand, period measures cannot completely indicate changes of fertility patterns due to timing and spacing effects.

As a result, the interpretations of fertility trends can be more dramatic with period measures than if we use completed cohort fertility measures. If we want to take advantage of each of the different measures one must search for a method which will predict cohort fertility.

Roughly we have three basic ways in which completed cohort fertility can be estimated: 1) the fertility patterns of preceding cohorts 2) information about changes of independent variables and 3 ) expectations and plans for future births.

In this paper we will use a survey (the Norwegian Fertility Survey 1977) and a follow-up study (births recorded among those same women for the period 1978-1982) to examine if an easy method is also a viable one. If so, this means that the responsibility of making fertility projections merely shifts from the forecaster to the women themselves.

\section{Fertility expectations and demographic analyses}

Questions about future fertility have a long and solid tradition in fertility surveys. The same is true with regard to the criticism of that kind of question (Ryder, 1973; Blake, 1974; and Simons, 1978). The discussion has to some degree been a methodological one, focusing on the validity and the reliability of the different measures, but it has also debated the utility of measuring birth expectations. We will not initiate a further discussion on either topic. Instead, we will briefly summarize opportunities and results in analyzing fertility expectations.

For this purpose we define fertility expectations as beliefs or ideas about future births. It can, for instance, be statements about the number of children desired or expected, the appropriate time for childbearing, how definitely women regard their fertility plans to be, and not least, if the respondents are both able and ready to answer questions about their own fertility intentions.

Future fertility orientations have been measured in a lot of varieties, inter alia: desires, plans, intentions, ideals, preferences and expectations. Although they may happen to be quite similar, they are not necessarily identical (Ryder, 1981). What we should bear in mind here, however, is a rough definition of future 
fertility orientation and therefore regard the various measures as more or less synonymous. Since fertility intentions strictly speaking exclude unwanted births (Ryder, 1981), and desires and ideals can be perceived as more hypothetical, we generally use the term expectation.

Analyses of birth expectations can be divided into two main topics:

A) Do birth expectations to some extent remain stable?

B) 'What is the relation between fertility expectations and fertility behaviour?

In both cases it will be most fruitful to study expectations at the beginning of women's family building period. When women are in their late thirties or in their forties, only a negligble part will expect future children.

Exploring the connection between fertility expectations and performance does not make sense unless we can suppose some kind of stability in expectations, or if there exists certain predictable patterns of alteration. Therefore, before we can discuss question B) which is the main topic of this paper, we have to tackle question A).

\section{A) The stability of fertility expectations}

Changes and stability in fertility plans can be explored both as an intercohort and intracohort phenomenon. Either the focus is on women in the same age group at different times or on women born in the same year as they age. The vast majority of conclusions have to be drawn from the United States where the greatest number of studies have been carried out. Although some of the studies are small-scale and limited to married women or even to married women with children, the United States has both the longest and most diversified tradition of fertility expectation surveys. One especially important step is the effort to gather time-series data, as done annually from 1967 in Current Population Survey (CPS) conducted by U.S. Bureau of the Census, in Growth of American Families surveys (GAF I 1955 and GAF II 1960) and in National Surveys of Family Growth (NSFG, 1973 and 1976).

If we focus on intercohort trends in anticipated childbearing, findings from Current Population Survey (CPS) show that as actual fertility has declined so has expected fertility. During the period 1965-1979, wives 18 to 34 years old reduced their lifetime birth expectations by about one child. For the youngest women (18 to 24 years) this tendency does not only reflect a lowering of expectations but also a greater difference in childbearing to date and anticipated childbearing. In 1965 married women 18 to 24 years old expected in total 3.1 children and had already born 48 percent of that number. Since then women in the same age group have reduced their lifetime birth expectation to 2.1 in 1976, and not more than 38 percent of the expected number were births to date (Current Population Report No. 369). It is too early to conclude, but it could well be that the younger cohorts not only lower their expectations, but are also more inclined to overestimate future childbearing than the preceding cohorts.

Data on single women, are not available prior to 1976. Including single women seems to reduce the expectations by maximum 6 percent (O'Connell and Moore, 1977). Married women $18-24$ years old in 1979 expected 2.3 children compared with 1.8 children for never married women (Current Population Reports No. 358). In 1981 the lifetime birth expectation dropped below the replacement level. The average number of lifetime birth expected was 2.0 children, and to that date they had only completed 25 percent (Current Population Reports No. 369).

The development of lifetime expected parity shows increasing preferences for 2 children and a decreasing expectation for larger families. Preferences for zero parity have not considerably increased since 1960 . In 1979, 6 percent of currently married women ( 18 to 34 years) expected to remain childless. For single women 
11 percent stated preferences for childlessness (Current Population Reports No. 358). Bloom and Pebley (1982) warn that we have to be careful about the validity of expectation measures especially regarding those young women who show a significant amount of uncertainty. They therefore hypothesize that the 11 percent figure is an underestimation of the proportion who intended to remain childless.

Analyses of the development of intracohort fertility expectations give ambiguous results, and point to period effects rather than to a general effect of aging. Comparison of cohorts 20-24 years with the same group five years later (at age 25-29) do not show any distinct downward revision of their plans (Campbell, 1981). Data from Current Population Survey does in fact show that the cohorts 1943-1947 reduced their expected number of children by 15 percent from 1967 (age 20-24) to 1972 (age 25-29). However, the reduction among the subsequent cohorts was considerably less.

The cohorts born 1950-54 had an insignificant increase in their expected number of births from ages 20-24 (1974) to ages 25-29 (1979). It must be kept in mind that the figures are based on currently married women only, and that the comparisons do not refer to panel studies but to different samples representing the same cohorts.

Several authors emphasize the desirability of studying all women, not only those currently married. Though the differences in birth expectations regarding marital status are small at younger ages, unmarried women are more inclined to change their original expectations as they grow older. It looks like a tendency to a slight decrease in birth expectations as cohorts grow older does not exist for married women at the different interview dates. In the $1970 \mathrm{~s}$ an observed decrease in fertility and a decline in the number of expected children, was true only for the women who were childless at the first interview (Shaw and Statham, unpublished). When the mean number of children expected remains unchanged for the women already mothers at the first date, it must be traced back to the fact that a minor part of their expectations is hypothetical. However, if we look only at the women who at the first interview said they expected more children, the two-children mothers are more inclined to reduce their intentions than the childless or one-child mothers. Shaw's and Statham's interpretation of this finding is that it is easier to revise plans when you already have reached the two children norm, and that the social disapproval can make it inconvenient to maintain decisions of childlessness or to be a one-child mother.

The scarity of time series data prevents a distinct answer to question A about the stability of birth expectations. However, studies from the United States indicate that although at the end of the $60 \mathrm{~s}$ there was a marked decrease in the expected number of children as the cohorts grew older, the development in the 70 s shows a remarkable stability. On the other hand, comparing fertility expectations of different cohorts shows an evident downward trend. This warns us about using birth expectations of young women to predict the fertility or even the expectations of cohorts not yet in childbearing age. In this way the opportunity to make real long-term predictions is excluded.

Westoff (1981) has also warned against taking the expectations as predictions of subsequent fertility. In his opinion fertility attitude measures reflect rather than anticipate changes. If this is true, the answer to question B ("What is the relation between fertility expectations and fertility behavior?) may also be less straightforward than originally anticipated.

\section{B) The relation between fertility expectations and fertility behaviour}

Several longitudinal studies seem to confirm that childbearing expectations at a young age can be a pretty good predictor of lifetime fertility. Although it may happen to be true only on an aggregate level and not for individuals, results like these are promising tools in attempts to predict future fertility. Closer examin- 
ations, however, have revealed that experiences of comparing expectations with later childbearing behavior are more confusing and less promising than at first glance.

Westoff (1981) reviews several longitudinal fertility studies, and concludes that the success of the attitude measures in predicting subsequent behavior can largely be traced back to a counterbalancing effect. So long as the outcome is such that the attitude measures predict future fertility rate with an accurancy ranging from 90 to 100 percent, it is irrelevant if the final figure includes both the over- and underestimated births. The trouble is that we have no guarantee that the effect will always be a counterbalance. The National Fertility Survey shows that although 41 percent of the women interviewed in 1970 , intended to have more children, only 34 percent of them actually had more children in 1975. Westoff (1981) interprets these findings as a result of $" . .$. an invalid assumption that the future would resemble the present. - Perhaps answers to questions about intentions are implicitly conditional: "This is how I think I will behave if things stay the way they are now, but if they don't, I may change my mind".

In the reappraisal of studies concerning fertility expectations and future fertility behavior, we will also draw attention to some other characteristic features.

The first one is a problem always recurring in panel studies, namely the drop-out problem. To study lifetime fertility the observation time has to be fairly long and it is almost inevitable to have a significant drop-out rate. It seems natural to suspect that women who are not reinterviewed may have fulfilled their fertility plans to a lesser degree than women reinterviewed once or more.

The second objection concerns the sample procedure, and is in our opinion a more serious one. Either in the original selection or in the selection in a sample for reinterviewing, the criteria often have been set in such a way that those women whom we will expect to have the largest discrepancy between fertility expectations and later childbearing, are eliminated. The Detroit study and the 1975 National Fertility Study included only women living in first marriage, the Princeton Fertility Study sampled only among parity two women, and the Kelly study excluded i.a. women who reported sterility problems or had adopted children. Although the total number of women excluded for such reasons is not too high, we lose very interesting groups.

We are only interested in the expectations and fertility behaviour on an aggregate level. However, a re-examination of the studies done, reminds us that fertility expectations are not only complex to measure, but that their significance as predictors, are at best mixed and at worst of little or no value. To test this statement, we will use data from the Norwegian Fertility Survey.

\section{The data}

The analysis is based on two different sets of data; a fertility survey (The Norwegian Fertility Survey 1977) and a register research (data extracted from the Central Population Register). The first one gives us information about the women's childbearing expectations in 1977. The second informs us of the number of realized births among these same women during the following 5 years (1978-1982).

Interviews were successfully completed with 4,137 women. The sample was representative of Norwegian women aged 18-44 years (born 1933-1959). The non-response rate was 18 percent. All the women interviewed were followed up in the register survey. Up to the end of 1982, 12 of them had died. The Central Population Register gives information of all births in the same period, excluding women who had emigrated or stayed abroad during all or a part of that period. 
Since some of the women may have emigrated or stayed abroad, it is impossible to give the exact number of drop-outs, but it can be estimated that about $2-2.5$ percent of the women in the most common childbearing age group, were abroad for the whole period or parts of it. Compared to dropouts in other longitudinal surveys this is quite insignificant.

Traditional analyses of fertility plans and later childbearing behavior are largely the result of various longitudinal studies. From these it is possible not only to gather information about the relationship between behavior and plans at an earlier stage, but also to extract new information about expectations or other factors which might have changed during the period of time. One of the problems of this traditional method of obtaining data is that the re-interview rates can be too low. Our method of collecting data can almost avoid that kind of problem. It is also a rather inexpensive method of doing follow-up studies, but we can up-date only the birth histories.

\section{Results}

Of the respondents in 1977, 42 percent expected to have children in the future, while the same percentage expected not to have children in the years to come. The question on expectations was given to childless women as well as to women who already had one or more children. Infecund and pregnant women are not included in the calculations. There was some uncertainty attached to fertility expectations. Fifteen percent of the respondents answered »Don't know» to the question on whether they expected a child or not. On a preceding question, an even higher percentage stated that they had not yet made up their minds on future childbearing. We have to take this as an important reminder that fertility interpretations have to allow for ambivalence and changes.

Quite naturally, it is the younger women who expect children in the years to come. Eighty-four percent of the women younger than 25 expected at least one birth in the future, while only 50 percent of the women in the last half of their twenties thought they still had births to come. The proportion expecting future children declines further to 19 percent among women $30-34$ years of age, and for the older women almost none expect to give birth in the future.

What would be the outcome of a comparison between expectations and behavior? As a beginning, we limit ourselves to only those who show conformity between expectation and behavior (the categories ++ and -- in Figure 1).

\section{Fig u re 1. Comparison between fertility expectations and later births}

\section{BEHAVIOR}

Children No children

EXPECTATION

\section{Children}

$++$

$+-$

No children

$-+$

$--$

Table 1 shows that almost all women who in 1977 expected not to have (more) children, have been consistent in their behavior. Five years after the interview, only 3 percent of them had had children. Those who expected a birth in the future, have so far (up to 1982) by no means fulfilled their expectations. As much as 51 percent among them have not yet had any birth.

The age of the women partly explains the high degree of accordance between negative expectations and later behavior. Among the women expecting to have terminated their childbearing in 1977 , four out of five were older than 30 years of 
$\mathrm{T}$ a b l e 1. Fertility expectations and fertility. The situation 5 years after the interview

$\begin{array}{cccc}\begin{array}{c}\text { Percent consistent } \\ \text { among women who }\end{array} & \begin{array}{c}\text { Num- } \\ \text { ber of }\end{array} & \begin{array}{c}\text { Percent consistent } \\ \text { among women who }\end{array} & \begin{array}{c}\text { Num- } \\ \text { ber of }\end{array} \\ \text { expected smore» } & \text { women } & \text { expected no more» women }\end{array}$

Age in 1977

$\begin{array}{lrrrr}\text { All } & 49 & 1485 & 97 & 1456 \\ 18-19 \text { years } & 36 & 265 & 5 \\ 20-24 \text { years } & 53 & 643 & 88 & 41 \\ 25-29 \text { years } & 54 & 411 & 90 & 228 \\ 30-34 \text { years } & 43 & 142 & 97 & 430 \\ 35-44 \text { years } & & 24 & 99 & 752 \\ \text { Parity status in } 1977 & & & 95 & 65 \\ 0 & 42 & 819 & 98 & 123 \\ 1 & 65 & 421 & 97 & 665 \\ 2 & 42 & 203 & 96 & 603\end{array}$

Use of contraception $1977^{*}$

Total

Did not use contraception

Did use coitus dependent methods (mainly condom, withdrawal, diaphragm, rhythm)

* Contraception the last 4 weeks before interview. This panel of the table comprise only women with intercourse in that period.

age. Consequently, the majority are at or close to ages where the age-specific fertility for a long time has been low. Of even greater importance might be that they are in the age group where the common expectations in the society about their childbearing have declined sharply. Table 1 also shows us that only 10 percent of women 25-29 years of age with negative fertility expectations, really had a child during the next 5 years. Even among women who still are in high-fertility ages, it seems like expectations of not to have a child are lived up to.

At the individual level, the correspondence between positive fertility expectations and later births is rather low. Even though they are not completely comparable, the results from earlier surveys are confirmed (Coombs, 1979a, Westoff, 1981). In Table 1, the women are divided according to age, parity and use of contraception at the time of the interview (1977) to reveal any differences in consistency. No subgroup can show higher fraction than $2 / 3$ who expected to have a child and really had one within 5 years.

The calculation by age shows that among women in the highest fertility age $(20-29$ years) at the time of the interview, slightly more than half have realized their expectations. The consistency percentage will, of course, increase as time passes. For the youngest (18-19 years) it is too early to make any estimates of their consistency rates. In 1982, they were 23-24 years of age, and could still have many future births. We also notice that among women $30-34$ years of age, only 43 percent of those with positive fertility expectations have fulfilled their plans. 
One-child mothers who expect children in the future, are more inclined to have at least another one than multiparas with the same expectations. Table 1 also shows that only 42 percent among childless women have realized their fertility expectations, at the time of the interview.

We have in another article (Noack and Østby, 1985) said that the modern contraceptive technology (Pill and IUD) changes the decision-making process connected with childbirth. As the use of contraception is not directly related to the intercourse, the decision-making process has to be more long-ranging and consistent. On this background we would expect that women who used the pill or IUD have realized their plans for future children to a lesser extent than other women. Table 1 confirms our expectation, but it is also possible that the choice of contraception reflects the strength of the fertility intentions: Women who are most convinced about having children in the future, have a tendency to use more traditional contraceptive methods.

\section{Waiting time to the next child}

Everyone who expected to have (additional) births in the future, were also asked at what time they wanted their (next) child. So, we can compare the desired time to the next birth with the actual births in the following 5 years (Table 2). Not more than 55 percent among the women who in 1977 stated that they wanted a (another) child within 5 years, had reached their goal by the end of 1982. The data broken down to more specified time periods, show little consistency between wanted delivery and the time the children were born. Whether this is caused by rapid changes in the wishes, or by a great discrepancy between stated wishes and reality, cannot be said. Further, the precoded response alternatives were not precise enough to justify too much attention to full agreement between wanted and realized time of birth.

Among all respondents, more births were wanted than were realized. In Table 3 we have compared the number of wanted births with the births all women in the survey had by the end of 1982 , irrespective of their expectations. During the 5 years $1978-1982$, the number of births to the respondents is 16 percent lower than the wishes from 1977 for the same period. The discrepancy between wanted and realized number of births is quite insignificant the first three years (Table 3). Even though individual misbeliefs counterbalance each other in the aggregate, we still find an overestimation of the number of births. The results are in accordance with O'Connell and Moore (1977), who found that women had approximately 10 percent fewer children than expected 5 years earlier (the period 1971-1976). Hendershot and Placek (1981) give results in the opposite direction. During a period of two years data from the National Survey of Family Growth (NSFG-I 1973 and NSFG-II 1976) showed that the respondents had 30 percent more children than they expected. This underestimation is explained as a result of unwanted births, assuming that unwanted births always are unexpected. When unwanted births are deleted there will be on the aggregate level no significant differences between births and expectations. They underline that a two years period is too short, and an underestimation after two years is counteracted by fewer births in the later part of a 5 years period.

As our results show overestimation, not underestimation, unwanted births cannot be the explanation of the difference between expectation and behaviour. Until we know whether or not there always will be a counterbalancing effect in the aggregate, and know in what direction a possible deviation will go, fertility expectations will be highly doubtful predictors of future fertility. 
$\mathrm{T}$ a b l e 2. Desired time to next births as compared to actual births in the following 5 years. Women who expected to have child(ren) in the future. Percent

\begin{tabular}{|c|c|c|c|c|c|c|}
\hline \multirow{2}{*}{$\begin{array}{l}\text { Wanted } \\
\text { children } \\
\text { within }\end{array}$} & \multicolumn{4}{|c|}{ ACTUAL BIRTHS } & \multirow{2}{*}{$\begin{array}{c}\text { No } \\
\text { births, } \\
1978- \\
1982\end{array}$} & \multirow{2}{*}{$\begin{array}{c}\text { Num- } \\
\text { ber } \\
\text { of } \\
\text { women }\end{array}$} \\
\hline & Total & $\begin{array}{l}1 \text { year } \\
(1978)\end{array}$ & $\begin{array}{c}1-2 \text { years } \\
(1979-1980)\end{array}$ & $\begin{array}{c}3-4 \text { years } \\
(1981-1982)\end{array}$ & & \\
\hline
\end{tabular}

\begin{tabular}{lrrrrrr}
$\begin{array}{l}\text { All women } \\
\text { wanting birth }\end{array}$ & 100 & 9 & 26 & 14 & 51 & 1485 \\
-1 year & 100 & 34 & 23 & 6 & 38 & 192 \\
$\begin{array}{l}1-2 \text { years } \\
\text { 3-4 years }\end{array}$ & 100 & 11 & 38 & 13 & 38 & 488 \\
$\begin{array}{l}\text { 5+ years } \\
\text { No definite }\end{array}$ & 100 & 2 & 23 & 18 & 57 & 394 \\
plans & 100 & 1 & 7 & 14 & 78 & 180 \\
\hline
\end{tabular}

T a b l e 3. Births wanted in 1977 during the following 5 years and children born during the same period ${ }^{\mathrm{l}}$

\begin{tabular}{lccc}
\hline Year & $\begin{array}{c}\text { Number of } \\
\text { births wanted } \\
\text { A }\end{array}$ & $\begin{array}{c}\text { Number of } \\
\text { children born } \\
\text { B }\end{array}$ & $\frac{\mathrm{B}-\mathrm{A}}{\mathrm{A}} \cdot 100$ \\
\hline $1978-1982$ & 1074 & 901 & -16 \\
1978 & 192 & 166 & -14 \\
$1979-1980$ & 488 & 469 & -4 \\
$1981-1982$ & 394 & 266 & -35 \\
\hline
\end{tabular}

1) Births among women pregnant or infecund in 1977 are excluded.

The tendency towards higher age at first birth - could it have been predicted?

Age at first birth is almost constant for every cohort 1933-1952 (Noack and Østby, 1981). But for the younger women, born 1953-1959, there have been considerable changes. Those who would have started their births in later part of the 1970 s if they had followed the age-specific fertility pattern from the 1950 s and $1960 \mathrm{~s}$, have a median age at first birth 0.7 years higher than their preceding cohorts, and it seems to be increasing in the years to come (Noack and Østby, 1985). It is well worth asking whether or not such a change in the fertility pattern could have been predicted on the basis of answers from young women in the Norwegian Fertility Survey.

Figures $2 \mathrm{a}$ and $2 \mathrm{~b}$ show realized, wanted and estimated first births during the 5 -year period after the interview. Information on the births is taken from the register research. Wanted births are births the women said they wanted within 5 years after the interview. Estimated births show the number of first births after 1977 given that the women had children according to the birth pattern of the 
Fig u r e 2 a a n d 2 b. Realized, wanted and estimated first births. Cumulative percentages.

a) Percentage with first birth in the cohort $1957-1959$ from the age of $18-20$ years to $23-25$ years, 5 years later.

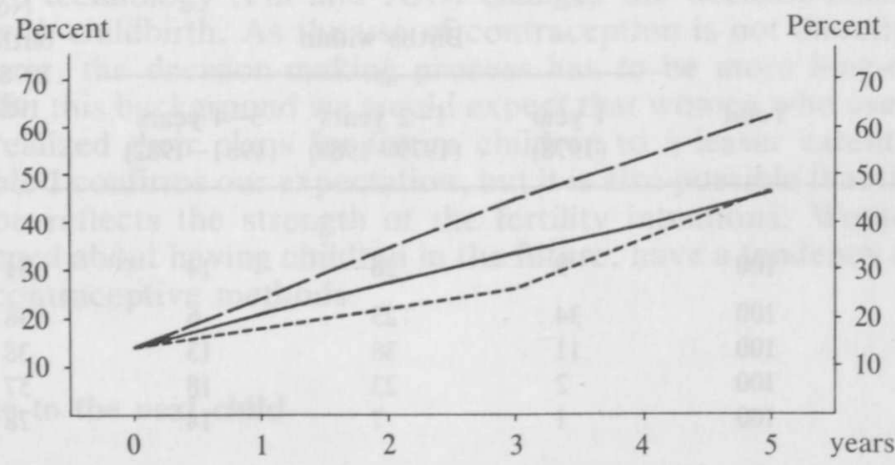

b) Percentage with first birth in the cohorts $1954-1956$ from the age of $21-23$ years to 26-28 years, 5 years later.

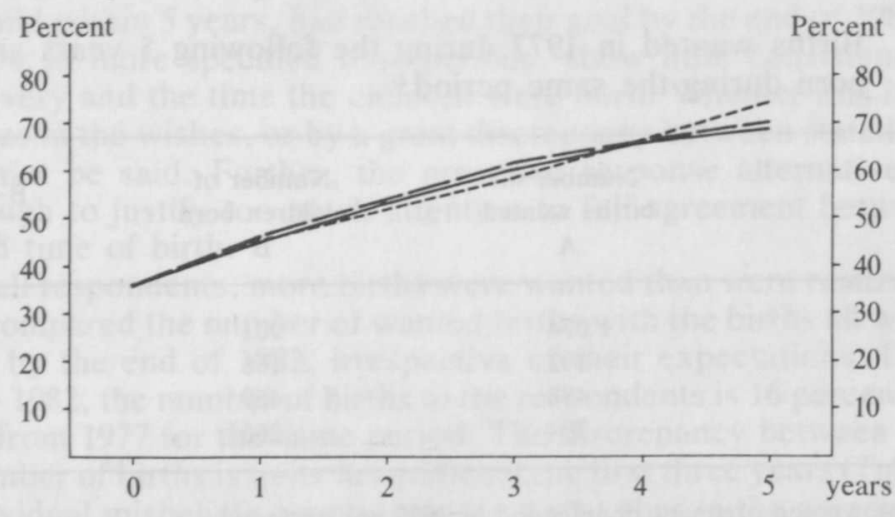

Realized first births

Wanted first births and first births among women pregnant at the time of the interview

First births estimated on the basis of the 1945-1950 cohorts age-specific pattern

1945-1950 cohorts. These are the youngest cohorts to be followed to age of 26-28 years. Cumulative percentages are calculated, they show the fraction of the cohorts who have/have not become mothers.

Among the youngest (born 1957-1959, 18-20 years of age in 1977) 14 percent were already mothers at the interview. Five years later (at an age of 23-25 years) 46 percent had at least one child (Figure $2 a$ ). Among women $21-23$ years of age in 1977 (born 1954-1956) 36 percent were mothers at the time of the interview, and 69 percent were mothers 5 years later (Figure $2 b$ ).

If the youngest women (Figure 2a) had had the same age-specific first-birth pattern as women of age $18-20$ at the end of the $1960 \mathrm{~s}$ and beginning of the $1970 \mathrm{~s}$, a considerably higher percentage among them would have had children. Our 
diagram with the estimated figures shows that 60 percent should have become mothers according to the 1970-pattern, while the observations give only 46 percent. For the preceding cohorts, Figure $2 \mathrm{~b}$ shows a good agreement between the estimates and the first births. However, among women born 1954-1956 there was a lower percentage of mothers at the beginning of the period: at $21-23$ years of age, 36 per cent had become mothers, while the percentage was about 45 in the 1945-1950 cohorts at the same age. The cohorts 1954-1956 had not yet managed to gain the lead the preceding cohorts already had established at the age 21-23.

Wanted births are in both Figures $2 \mathrm{a}$ and $2 \mathrm{~b}$ almost in full agreement with the realized births. From these aggregate-level figures then, it could have been possible to predict the delay of first births which actually have taken place the years after the interview.

However, once more it seems appropriate to question whether a good agreement on the aggregate level could be a coincidence. Only 54 percent of the childless women (born 1954-1959) who expected to become mothers in the period, really did so, and only one quarter of the women had their children exactly in the period they wanted. The correlation between wanted and realized births on the individual level is not as promising as Figures $2 \mathrm{a}$ and $2 \mathrm{~b}$ indicate at first sight, but this might be one of several methods which combined with ofthers may constitute a better basis for predicting fertility.

\section{Discussion and conclusions}

In the evaluation of our results, we have to point out that we have used the predictive value only for a short time interval (maximum 5 years), and limited ourselves only to the outcome birth/no birth. Comparisons between fertility expectations and completed cohort fertility, especially for a somewhat longer period have traditionally been held as more promising. In not too many years. even the youngest respondents from 1977 have enough of their childbearing period behind them to make possible comparisons between total expected number of children and their actual fertility.

Even though expectations are measured in most fertility surveys, it seems that there still is a need for more and better surveys. There is a serious lack of panel surveys with possibilities to analyze the agreement between expectations and behavior on the individual as well as on the aggregate level. Demographers and sociologists have also worked on more valid methods to measure expectations. A well known example is Coombs (1976b) scale for measuring underlying preferences, not only a single number. Much still seems to be done on the changes in fertility expectations. Partly, there is a lack of good time series data, partly there is some ambiguity about the interpretation of the changes. Aging processes (life cycle changes, cohort- and period effects) might cause changes in the fertility expectations. There is, however, much complex empirical work to be done before it will be possible to distinguish between the various effects.

Our conclusion is not only a wish for more data and refinement of methods and techniques. We also find it necessary to look for new approaches. It might be possible that fertility expectations, whether we call them wants, intentions, ideals or others, are too narrow a segment of the whole picture. The aim should be to analyze fertility norms in the traditional sociological sense of the word norms. Udry (1982) states that the concept "norm» used in studying fertility, has very little in common with the sociological concept. Most of the fertility surveys consider only statements, while the most crucial point, the question on sanctions and consensus very often is deleted. Udry asks for surveys of normative expectations and normative beliefs (e.g. questions like "How do you think your parents/friends/colleagues would react if you became pregnant", or decide upon statements like "My parents think I should have a child within the next two 
years".) It can easily be objected that these kinds of questions present the projections of the respondent more than the real sanctions or consensus in their groups of reference. Udry states that the nuances in the answers indicate that it is not only the wishes of the respondents that are surveyed. In his data, less than 50 percent of the respondents anticipated only positive or only negative reactions from their groups of reference.

Udry shows that expected normative responses from friends, neighbours and the family might be a good predictor on short-term fertility (1-2 years). The predictive power is by far the best for couples who are childless at the beginning of the expected period. Udry included interviews with husbands, and the normative responses these expressed also seemed to have a great influence on the short term fertility if the couple were childless at the beginning of the period.

Another example of the use of the sociological concept »norm», is the "age norm". This implies that there exists expectations about when the various life cycle changes (e.g. end of education, marriage, first birth) most favorably should take place, and that one experiences negative sanctions if for some reason one does not follow the prescribed pattern. Hagestad and Neugarten (1984) give three groups of age norms: "The three P's (permission, proscription and prescription) with regard to role entries and exits, time tables, and norms regarding other kinds of age-appropriate behavior".

The postponement of first births showed in this article might partly be a result of changing norms concerning entry into motherhood. If this delayed entry is not followed by a delay concerning the exit as well, we might expect a new fertility decline.

Hitherto, demographic research has placed very little attention on age norms. Modell (1980) is one example on this approach. He makes comparisons of ideal and actual age at marriage, and presupposes that first marriage as well as first birth will be normatively scheduled. To be in accordance with the schedule, does not only mean the absence of negative sanctions, but that there also exists an important social support in having the same experiences as the peer group at the same time.

As compared to the traditional measures of expectations, we think that norms generally, and age norms in particular may give a better basis for making assumptions about the future, but not neccessarily giving us precise predictors. However, in the same way as with the traditional measures of expectations, the causes of changes of the norms and the effects of historical events and structural conditions are unsolved problems.

\section{References}

Blake, Judith (1974). Can we believe recent data on birth expectations in the United States? Demography 11: $25-44$.

Bloom, David E. and Pebley, Anne R. (1982). Voluntary childnessness: a review of the evidence and implications. Population Research and Policy Review 1: 203-224.

Campbell, Arthur A. (1981). Needed research on birth expectations. In: Predicting fertility edited by Gerry E. Hendershot and Paul J. Placek. Lexington Books, Lexington.

Coombs, Lolagene C. (1979a). Reproductive goals and achieved fertility: a fifteen-year perspective. Demography 16: 523-534.

- (1979b). Prospective fertility and underlying preferences: a longitudinal study in Taiwan. Population Studies 33: 447-455.

Hagestad, Gunhild O. and Neugarten, Bernice L. (1984). Age and the life course. In: Handbook of aging and the social science edited by R. H. Binstock and E. Shanas. Van Nostrand Reinhold Co, N.Y., in press. 
Hendershot, Gerry E. and Placek, Paul J. (1981). The validity and reliability of birth expectations: evidence from National Survey of Family Growth and the National Natality Survey. In: Predicting fertility edited by Gerry E. Hendershot and Paul J. Placek. Lexington Books, Lexington.

- eds. (1981). Predicting fertility. Lexington Books, Lexington.

Modell, John (1980). Normative aspects of American marriage timing since World War II. Journal of Family History 5: 210-234.

Noack, Turid and Østby, Lars (1981). Fruktbarhet blant norske kvinner. Resultater fra Fruktbarhetsundersøkelsen 1977. Samfunnsøkonomiske studier nr. 49. Statistisk Sentralbyrå, Oslo.

- (1985). Færre barn - en utfordring for helsesektoren? Tidsskrift for samfunnsforskning 1-2. In press.

O'Connel, Martin and Moore, Maurice J. (1977). New evidence on the value of birth expectations. Demography 14 (3): 255-264.

Ryder, Norman B. (1973). A critique of the National Fertility Study. Demography 14 (4): 431-453.

- (1981). Changes in parity orientation from 1970 to 1975 . In: Predicting fertility edited by G. E. Hendershot and P. J. Placek. Lexington Books, Lexington.

Shaw, Lois B and Statham, Anne (Unpublished). Changes in birth expectations, 1973-1978.

Simons, John (1978). Illusions about attitudes. In: Population decline in Europe. Chapter 9. Council of Europe, Strasbourg.

Udry, Richard J. (1982). The effect of normative pressures on fertility. Population and Environment 5: $1-18$.

U. S. Bureau of the Census (1980). Fertility of American women: June 1979. Current Population Reports, Series P-20, No. 358.

- (1982). Fertility of American women: June 1981. Current Population Reports, Series P-20, No. 369.

Westoff, Charles F. (1981). The validity of birth intentions: evidence from U.S. Longitudinal Studies. In: Predicting fertility edited by G. E. Hendershot and P. J. Placek. Lexington Books, Lexington. 